\title{
Application of function analysis to bathing areas in the Maltese Islands
}

\author{
Micallef, Anton S. ${ }^{1} \&$ Williams, Allan T. ${ }^{2}$ \\ ${ }^{1}$ Euro-Mediterranean Center on Insular Coastal Dynamics, Foundation for International Studies, University of Malta, \\ Valletta VLT 07, Malta ; ${ }^{2}$ Applied Science Department, University of Glamorgan, Pontypridd, Wales, UK
}

\begin{abstract}
On a small island such as Malta where many developers and policy makers place a large emphasis on social use and development values, which encourages recreational/industrial development, it is often hard to promote the monetary value of coastal conservation due to strong competition with the large tourism industry. An assessment of the ecological (conservation) and economic (use/development) values of four popular Maltese bathing areas (Mellieha, St. George's, Ramla and Ghajn Tuffieha Bay) was carried out by evaluating their ability to provide a number of functions. This is dependent on the environments' inherent characteristics within the context of locally applicable time and space functions. Function Analysis is an innovative technique able to provide a means for assessing changes in environmental quality of an area and evaluating the sustainability of applied management regimes. This paper is a first example of an application of the Functional Analysis approach in Malta. Local application of this technique indicates a need for additional refinement in application to coastal areas. Analysis showed that St. George's, had the lowest conservation value, Ramla and Ghajn Tuffieha bay had the highest conservation values, Mellieha Bay had high conservation value and use/development potential. In this context, conservation value is understood to reflect values of biodiversity, information / knowledge and environmental quality.
\end{abstract}

Keywords: Bathing area; Conservation value; Environmental quality; Function analysis; Function of nature; Recreation; Use/development value.

\section{Introduction}

The characterization of a coastal environment by its ecologic value (conservation potential) and social value (use/development potential), allows assessment of the degree of sustainability of a given/envisaged management regime for that area. However, such characterization requires an expression (normally in monetary units) of the economic and ecological values. It is still very difficult to reach agreement on an acceptable expression of ecological value in monetary terms and a number of alternative approaches to assessing ecological and social values have been considered.

Van der Maarel $(1978,1979)$ and de Groot (1992) approached the assessment of ecological and social values of an environment by considering goods and services provided by various processes and components within that environment. The authors referred to the goods and services (or the social values) as the functions of nature, while the processes and components represented the natural environmental characteristics of that same environment. This approach is referred to as Environmental Function Analysis. It considers the natural environmental characteristics of an environment and their ability to provide environmental goods and services (i.e. environmental functions) and may be employed as a planning and decision making tool.

Classic early work namely by van der Maarel (1978, 1979) later developed by de Groot (1992), culminated in the identification of four main functions, namely: 1. Production functions - these include all kinds of renewable and non-renewable resources.

2. Carrier functions - providing space and substrate for human activities.

3. Information functions - provision by nature of reflection, spiritual and cognitive enrichment and signal functions.

4. Regulation functions - capacity of ecosystems to regulate essential ecological processes which in turn, contribute to a healthy environment (e.g. clean air, 
Table 1. Regulation and information functions of nature identified by van der Maarel (1978, 1979) and de Groot (1992).

Regulation functions - capacity of ecosystems to regulate essential ecological processes which in turn, contribute to a healthy environment (e.g. clean air, water, soil).

Protection against harmful cosmic influences

Regulation of the local and global energy balance

Regulation of the chemical composition of the atmosphere

Regulation of the chemical composition of the oceans

Regulation of the local and global climate (+ hydrological cycle)

Regulation of run-off and flood prevention (watershed protection)

Water-catchment and ground water recharge

Prevention of soil erosion and sediment control

Formation of topsoil and maintenance of soil fertility

Fixation of solar energy and bio-mass production

Storage and recycling of organic matter

Storage and recycling of nutrients

Storage and recycling of human waste

Regulation of biological control mechanisms

Maintenance of migration and nursery habitats

Maintenance of biological and genetic diversity

Information functions - provision by nature of reflection, spiritual and cognitive enrichment and signal functions.

Aesthetic information

Spiritual and religious information

Historic information (of heritage value).

Cultural and artistic inspiration.

Scientific and educational information.

water, soil).

While fulfilment of production and carrier functions leads to a more or less drastic change in the landscape, this is not the case with regulation and information functions. However, the more the latter two functions are disrupted, the bigger the potential disruption of the production and carrier functions.

In defining such functions of nature, it should be noted that carrier and production functions largely represent social (economic) values, with direct use products having a direct value that can be assessed by common economic methods. Such social values may include both health and option values, the latter referring to the importance people attribute to a safe future (i.e. the future availability of a given amenity or service). Social values may be quantified by establishment of standards for lowest acceptable requirements of any goods or services.

Conversely, regulation and information functions represent mainly the conservation value of ecological values (Table 1), having indirect use products with indirect values that cannot be assessed by common economic methods. Ecologic values may also comprise of existence value which refer to intrinsic and ethical values having respect to the natural environment (e.g. concept of stewardship). Such functions are generally assessed by more qualitative methods (including interview surveys such as the Travel Cost Method and Contingent Valuation
Method).

De Groot (1992) described the relationship between environmental functions and environmental characteristics by drawing a matrix of the two aspects, focusing on those environmental characteristics that represent important criteria for evaluating the capacity of nature (an area/ecosystem) to provide certain functions. Interactions between the natural environment and human society, have also been described by van der Meulen \& van der Weide (1999) as having both positive and negative outcomes that can be divided into four main types:

1. Provision of environmental goods and services by natural processes and components.

2. Production of risks \& hazards by the natural environment.

3. Production of negative human impacts on the natural environment by human activities.

4. Development of human environmental management regimes to control their interaction with nature.

In Environmental Function Analysis, the capacity of a given (semi-) natural ecosystem to provide certain goods and services (environmental functions) depends on its environmental characteristics (natural processes and components). In a theoretical consideration of the Functional Analysis approach, Cendrero \& Fischer (1997) proposed a technique for assessing environmental quality of coastal areas through characterization of 
Table 2. Value allocation and calculation of normalized scores for bathing area-relevant coastal parameters. Scale used for total score allocation for ecological and social values $(1=$ minimum $-3=$ maximum $)$ - adapted from Cendrero \& Fischer (1997).

\begin{tabular}{|c|c|c|c|c|c|c|}
\hline \multirow[t]{2}{*}{ Environmental component } & \multirow[t]{2}{*}{ Characteristic } & \multirow[t]{2}{*}{ Indicators } & \multicolumn{4}{|c|}{ Evaluation of characteristics } \\
\hline & & & St. George & Mellieha & Ramla Bay & $\begin{array}{l}\text { Ghajn } \\
\text { Tuffieha }\end{array}$ \\
\hline \multicolumn{7}{|l|}{ Ecologic values } \\
\hline \multirow[t]{4}{*}{ Air } & Pollution & Gravity & 1 & 3 & 2 & 3 \\
\hline & & Visibility & 3 & 3 & 3 & 3 \\
\hline & & Effect on humans & 1 & 2 & 2 & 3 \\
\hline & & Normalized score & 0.583 & 0.833 & 0.833 & 1.000 \\
\hline \multirow[t]{4}{*}{ Coastal waters } & Quality & Microbiological pollution & 2 & 2 & 3 & 3 \\
\hline & Aesthetic condition & Turbidity & 3 & 3 & 3 & 2 \\
\hline & & Floating debris & 3 & 2 & 3 & 3 \\
\hline & & Normalized score & 0.889 & 0.778 & 1.000 & 0.889 \\
\hline \multirow[t]{2}{*}{ Fresh water } & Supply & Rainfall & 1 & 2 & 3 & 2 \\
\hline & & Normalized score & 0.333 & 0.667 & 1.000 & 0.667 \\
\hline \multirow{4}{*}{ Terrestrial biota } & & Natural vegetation cover & 1 & 2 & 3 & 3 \\
\hline & & Biological diversity & 1 & 2 & 3 & 3 \\
\hline & & Species of special interest & 1 & 3 & 3 & 3 \\
\hline & & Normalized score & 0.333 & 0.667 & 1.000 & 1.000 \\
\hline \multirow{5}{*}{ Marine biota } & Quantity & Biomass & 1 & 3 & 2 & 2 \\
\hline & & Biological productivity & 1 & 3 & 2 & 2 \\
\hline & Diversity & Biological diversity & 3 & 3 & 3 & 3 \\
\hline & & Species of special interest & 2 & No Data & No Data & No Data \\
\hline & & Normalized score & 0.583 & 1.000 & 0.778 & 0.778 \\
\hline \multirow{4}{*}{$\begin{array}{l}\text { Geological and topographic } \\
\text { features }\end{array}$} & & & & & & \\
\hline & & Lithological & 1 & 2 & 3 & 3 \\
\hline & & Size of bathing area & 1 & 3 & 2 & 2 \\
\hline & & Normalized score & 0.333 & 0.833 & 0.833 & 0.833 \\
\hline \multirow[t]{5}{*}{ Hazards } & & Coastal erosion & 1 & 2 & 2 & 3 \\
\hline & & Coastal flooding & 2 & 3 & 3 & 3 \\
\hline & & Storms & 1 & 3 & 2 & 1 \\
\hline & & Cliff/slope instability & 3 & 3 & 2 & 1 \\
\hline & & Normalized score & 0.611 & 0.944 & 0.722 & 0.667 \\
\hline \multirow[t]{8}{*}{ Resources } & Non-renewable & Minerals, rocks, construction & & & & \\
\hline & & materials, fuels & 1 & 1 & 1 & 1 \\
\hline & & Soil & 1 & 2 & 3 & 2 \\
\hline & Renewable & Fish & 1 & 1 & 1 & 1 \\
\hline & & Visual quality & 1 & 2 & 3 & 3 \\
\hline & Landscape & Uniqueness & 1 & 3 & 3 & 3 \\
\hline & & Normalized score & 0.333 & 0.600 & 0.733 & 0.667 \\
\hline & & Total & 46.000 & 65.000 & 68.000 & 65.000 \\
\hline \multicolumn{2}{|c|}{ Normalized score for ecologic values } & & 0.511 & 0.802 & 0.840 & 0.802 \\
\hline \multirow[t]{2}{*}{ Human component } & Characteristic & Indicators & Eva & luation of ch & haracteristics & \\
\hline & & & t. George & Mellieha I & Ramla Bay & $\begin{array}{l}\text { Ghajn } \\
\text { Tuffieha }\end{array}$ \\
\hline Social values & Potential for use & Historic, artistic, archaeological sites & 1 & 2 & 3 & 2 \\
\hline & & Public recreation facilities & 1 & 3 & 2 & 1 \\
\hline & & Hotels, restaurants & 3 & 3 & 1 & 1 \\
\hline & & Utilities & 3 & 3 & 1 & 1 \\
\hline & & Parking & 1 & 3 & 2 & 2 \\
\hline & & Accessibility & 3 & 3 & 3 & 1 \\
\hline & & Land use & 3 & 3 & 1 & 1 \\
\hline & & Extent of development & 3 & 3 & 1 & 1 \\
\hline & & Population density & 3 & 2 & 1 & 1 \\
\hline & & Intensity of use & 2 & 3 & 2 & 2 \\
\hline & & Extent of reclamation (with nourishment) & 2 & 1 & 1 & 1 \\
\hline & & Public health & 1 & 3 & 2 & 2 \\
\hline & & Opportunity for employment & 3 & 3 & 1 & 1 \\
\hline & & Perception of the quality of the environment & 1 & 2 & 3 & 3 \\
\hline & & Total & 30 & 37 & 24 & 20 \\
\hline Normalized score for soci & alues & & 0.714 & 0.881 & 0.571 & 0.476 \\
\hline
\end{tabular}


conservation value and use/development potential.

This and the technique's ability to effectively integrate scientific evaluation into the decision making process were presented as a direct contribution to coastal planning and management. The proposed technique involved a four-step approach:

1. Definition of area boundaries and selection of homogeneous land-use units within this boundary.

2. Identification of characteristic parameters for the environment in question that describe and distinguish between the environmental and socio-economic components of that environment. Based on an exhaustive list of environmental components and characteristics, Cendrero \& Fischer (1997) considered aspects specific to coastal areas in order to identify the relevant environmental characteristics that describe the ecological (natural) and socio-economic (human use) components of that environment.

3. Allocation of values to the characteristic parameters identified.

4. Comparison of natural (ecologic) value with human (use/development potential) value to determine sustainable development strategy.

Taking into consideration the ethos of integration in Environmental Management, each of the environmental functions identified (i.e. Regulation, Carrier, Production and Information functions) should be considered in terms of its social, economical or ecological value.

\section{Methods}

Cendrero \& Fischer's (1997) exhaustive list of ecological and socio-economic aspects developed for evaluating coastal areas, was adapted to better describe the natural and human use components of the local (Maltese) bathing area environment (Table 2). Based on the underlying principle of the methodology proposed by Cendrero \& Fischer (1997) that only those parameters that are considered applicable to the specific environment being evaluated should be valued by the environmental evaluation technique (in this case, bathing area), a number of environmental aspects considered by the authors were omitted during a baseline study of local bathing areas in Malta.

From a national (Maltese) coastal perspective, the absence of river, open freshwater and large woodland systems resulted in aspects of 'river flow, lake volume, freshwater floating debris, the availability of timber as a renewable resource, river flooding and sedimentation' to be omitted from the current study. Tsunamis, earthquakes and volcanic eruptions that are, in recent history, anomalous to the Maltese coastal environment were similarly not evaluated. From a beach-specific perspective, certain indicators used by Cendrero \& Fischer (1997) for the general coastal environment were replaced with more appropriate parameters. In this context, red tides were replaced with eutrophication, assessment of pollution levels was considered with respect to run-off, coastal and soil erosion were evaluated in relation to beach erosion and the extent of (beach) nourishment rather than coastal reclamation was considered. In addition, this study applied a simplified version of the exhaustive approach adopted by Cendrero \& Fischer (1997). This was based on the promising results already obtained by van der Weide et al. (1999) in their application of a smaller version of the technique to two beach/wetland systems in Turkey. Their objective was to identify easy to apply but scientifically sound management techniques applicable to bathing area management. The Cendrero \& Fischer (1997) approach was adapted in two main modes:

1. The omission of parameters requiring detailed studies and data not readily available e.g. detailed knowledge on the impact of atmospheric and water pollution on vegetation/humans or general public health and opportunities for employment.

2. A simplified scoring system based on the Cendrero \& Fischer (1997) approach, which omitted complex weighting techniques. This approach has been previously successfully tested by van der Weide et al. (1999).

Environmental Functional Analysis was applied to four local beaches in Malta (Mellieha, St. George's, Ghajn Tuffieha and Ramla Bay - Plates 1-4). Using extensive site visits and desk studies of site relevant reports where available, the analysis of each beach was carried out in a four-step process:

1. The environmental functions considered to be available at the beach in question were identified using the revised list of indicators of environmental and human components adapted to better reflect the local coastal environment and having direct relevance to the use of bathing areas (Table 2).

2. Using a Delphi interview method described by Anastassova (1996) as a forward-looking process utilising expert opinion to solicit best thinking for evaluation purposes, use-values were attributed to the ecologic and social values identified as being provided by beach environments. The value allocated, ranging from 1 (the lowest value) to 3 (the highest) were determined by evaluating human demand for such environmental functions (as carried out in similar desk and field studies by van der Weide et al. 1999). It should be noted that value allocation may be subjective, depending for example, on one's well-being or personal preferences. In addition, only parameters which are considered applicable to the specific envi- 


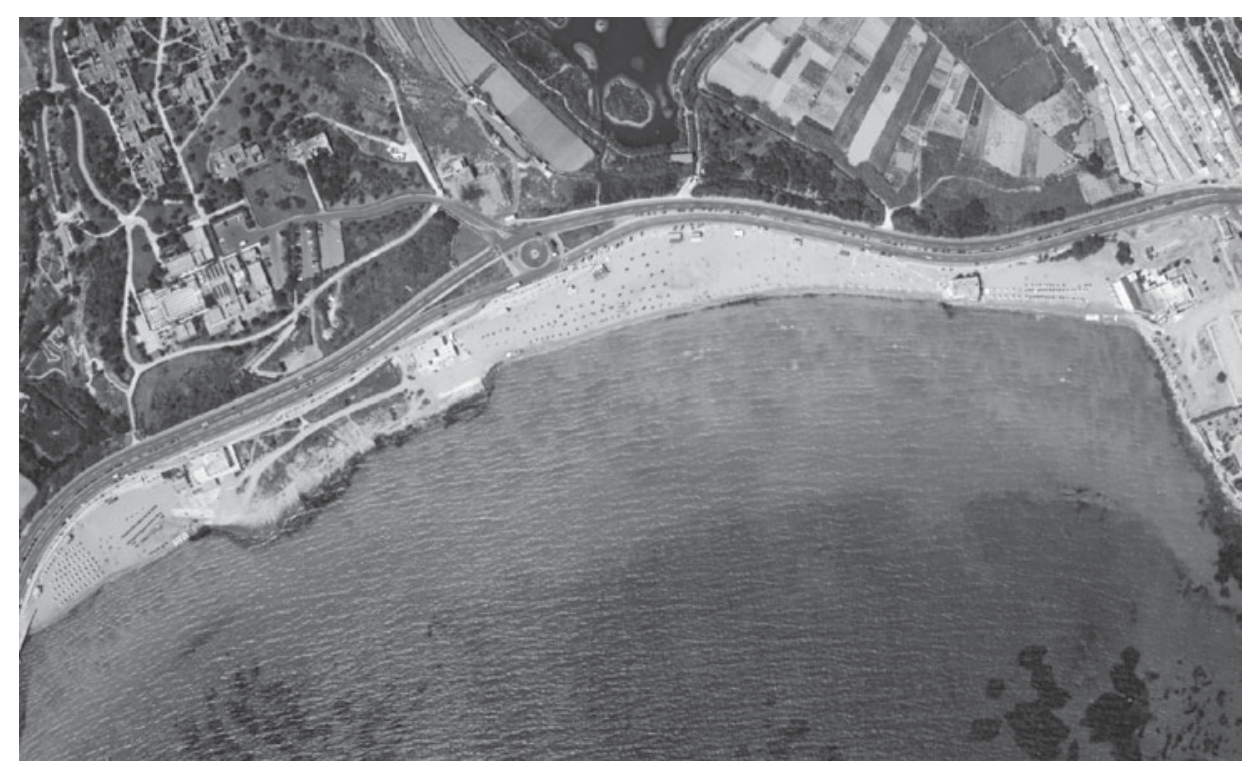

Plate 1. Mellieha Bay on the north coast of Malta. The presence of a Bird Reserve (seen on the top right corner of the image) was considered to influence an environmental evaluation of this site despite its characterization as a large resort beach.

ronment being evaluated, should be valued - see adapted parameter considerations specific to Maltese environment).

3. The scores for individual beach aspects were normalized to represent the conservation and use/development potential value as a non-dimensional parameter ranging from 0 (no value) to 1 (max. value). In order to normalise the value for each component e.g. air, coastal waters, marine biota, etc., the sum of the values attributed to the characteristics of that component was divided by the maximum possible score which could be allocated to that environmental component (i.e. $3 \times$ number of characteristics considered for that component).

4. Similarly, the total of the values allocated to all parameters was normalised (separately) for the subtotal of the ecological characteristics and the socioeconomic characteristics. The normalised values attributed to individual environmental components as well as the totals for the ecological and socio-economic characteristics were plotted as a bar chart (value on ' $\mathrm{Y}$ ' axis and characteristic on ' $\mathrm{X}$ ' axis) so as to better identify individual problem areas (Figs. 1 and 2).

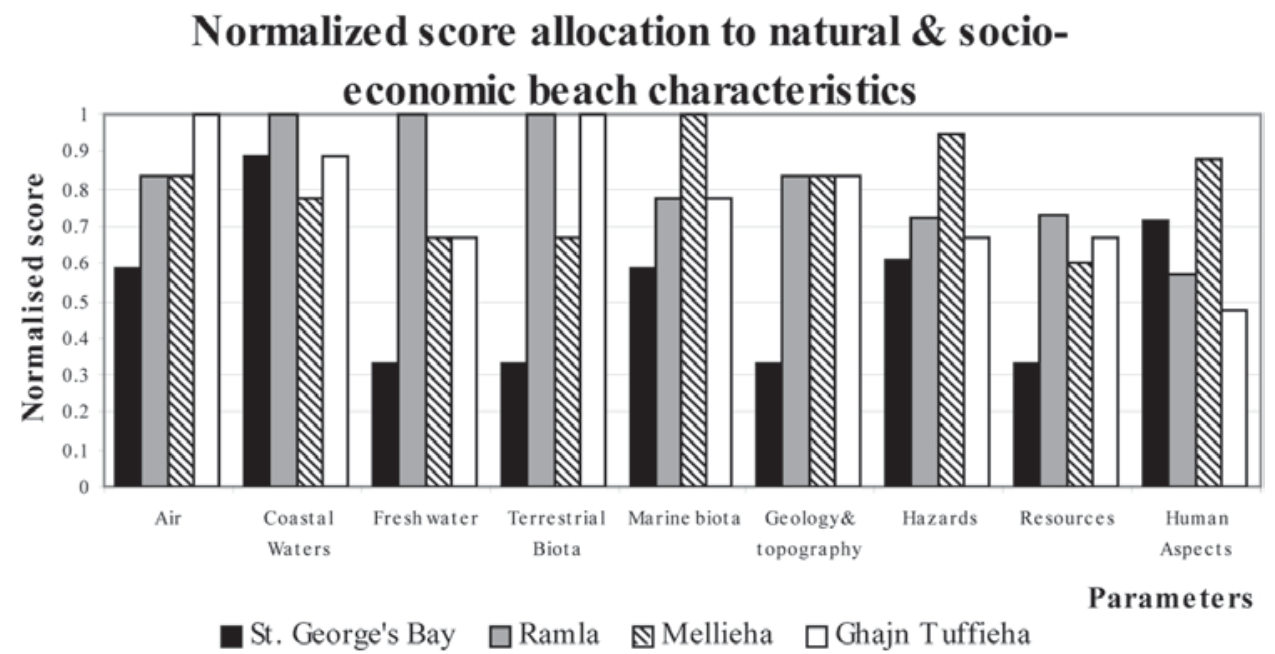

Fig. 1. A graphical illustration of normalized scores allocated to environmental and human components (see Table 2) of the four study beaches. 


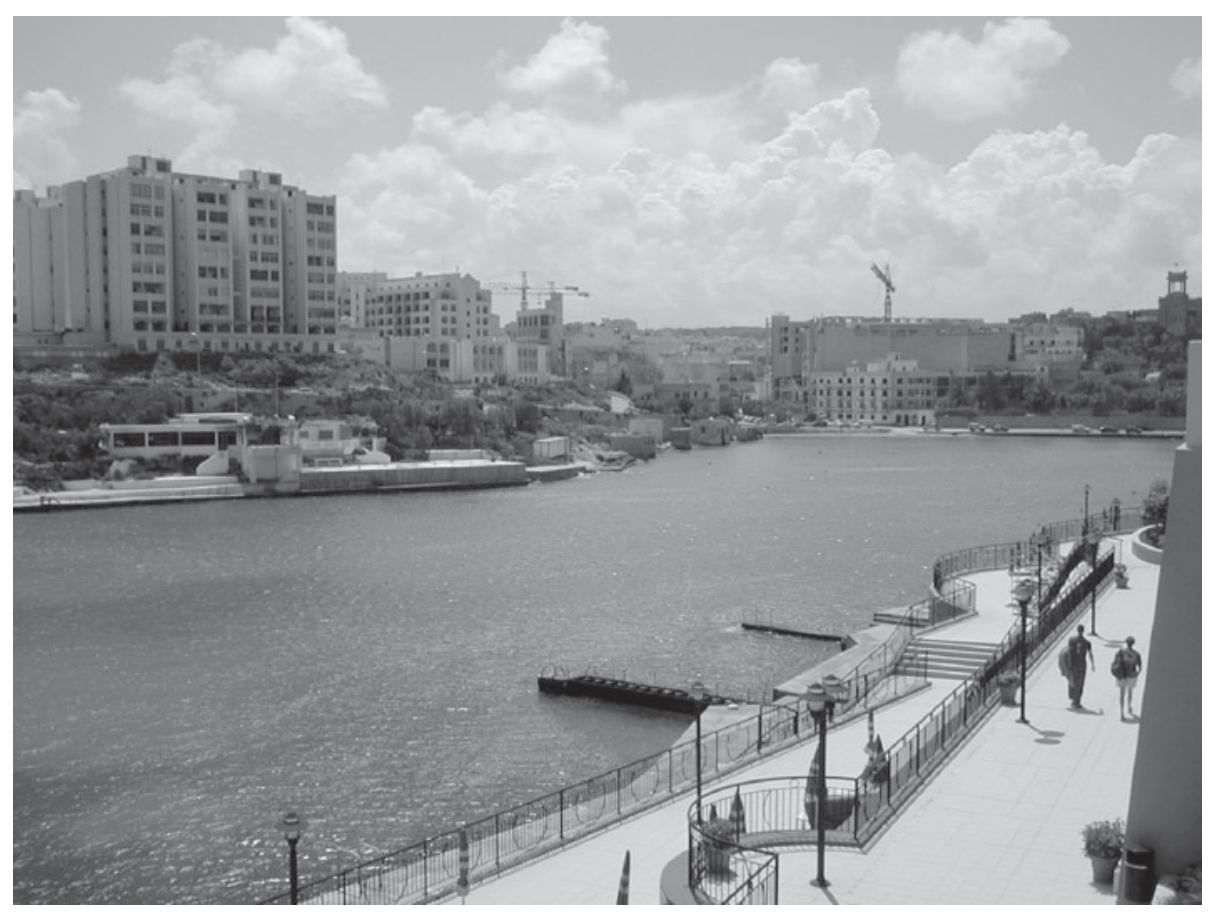

Plate 2. A tourist dominated St. George's Bay on the north coast of Malta.

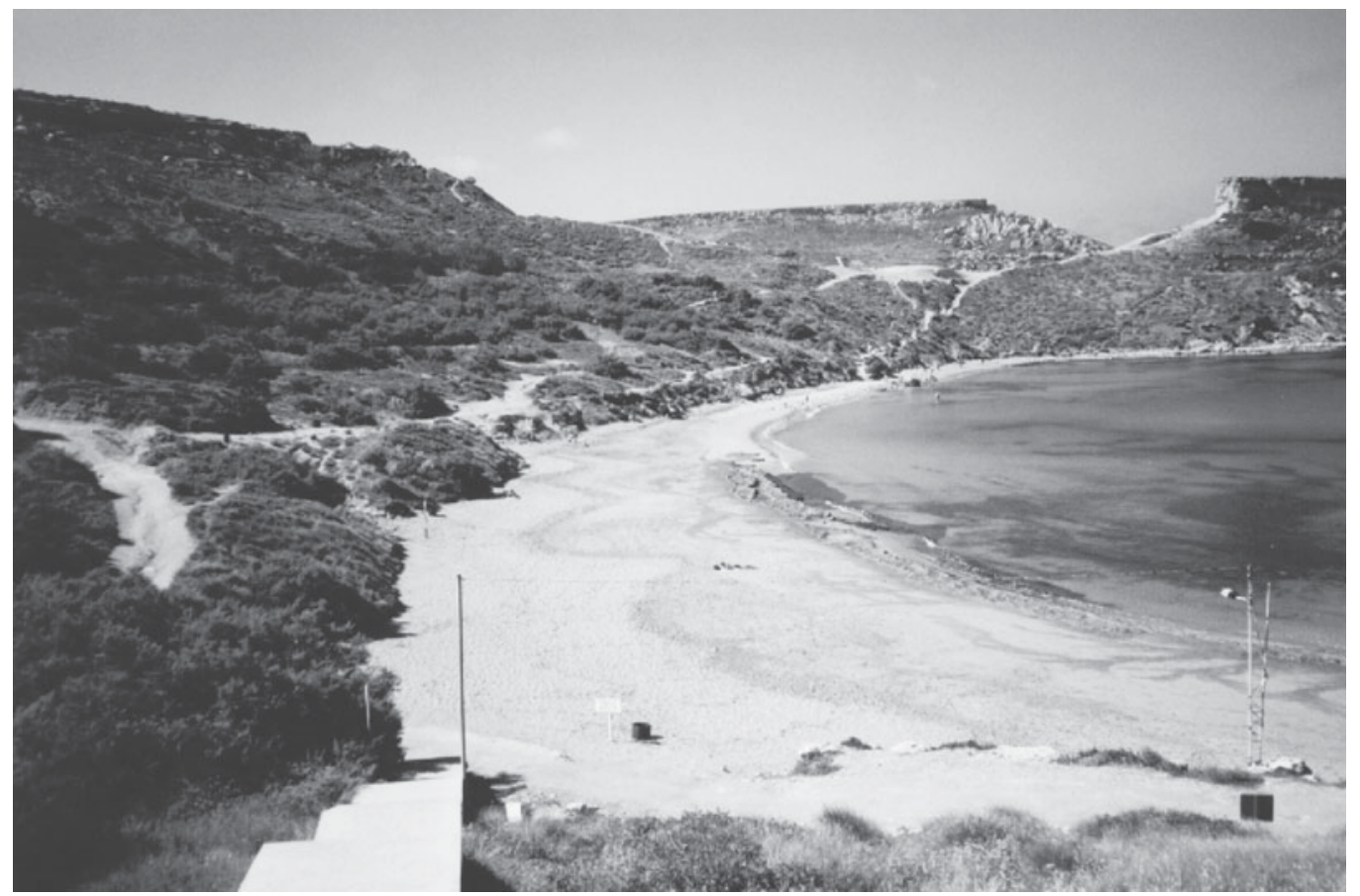

Plate 3. A rural beach at Ghajn Tuffieha Bay, scheduled as an Area of Ecological Importance (AEI) and Site of Scientific Importance (SSI). 


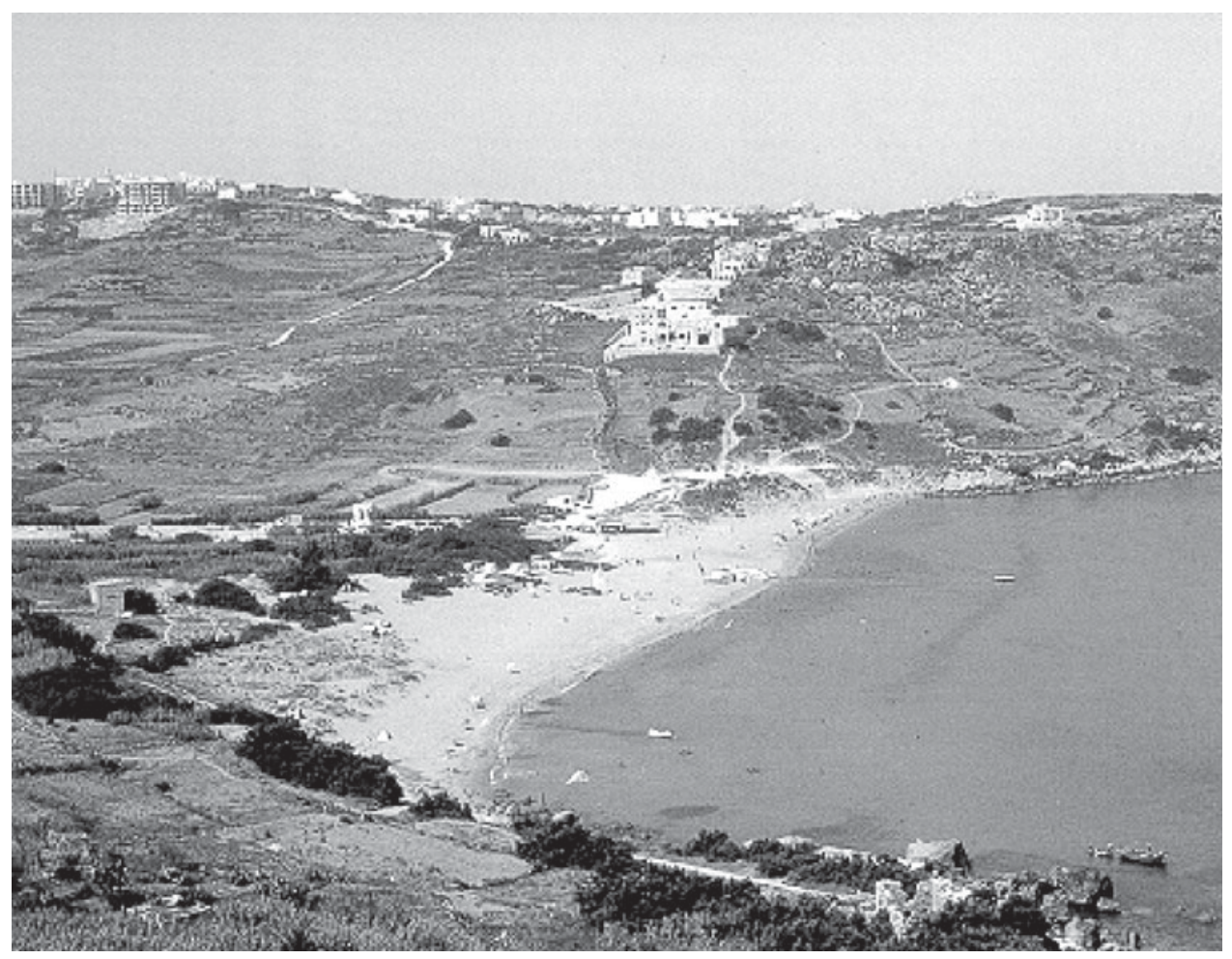

Plate 4. Ramla beach on the island of Gozo, characterized by a natural and argricultural landscape and possessing Malta's best preserved sand dune remnants.

\section{Results}

Based on the data provided by Table 2, normalized scores allocated to bathing area-related parameters were compared (Figs. 1 and 2). For ease of presentation, the human (socio-economic) parameters are grouped under one heading.

Fig. 1 describes the natural and socio-economic performance of St. George's Bay (Plate 2) on the northern coast of Malta. It may be seen that of the environmental functions, only those provided by coastal waters were rated higher than the human use value of the area. The high value attributed to coastal waters (and to a lesser degree, marine biota) may be related to the particularly rich biota associated with the abundant sea-grass meadows and clear, clean waters) present in this embayment. The relatively high hazard factor may be explained by the embayment's exposure to the north and northeasterly winds and the potentially damaging sea-state and precipitation related storm events influenced by a large catchment area. This highlights the need to address this issue in the planning of a management regime for this bathing area. Fig. 1 also reflects that freshwater, terrestrial biota and geological and topographical features (and to a lesser degree, natural resources) at St. George's Bay, perform poorly in Function Analysis.

At Mellieha Bay, (Fig. 1, Plate 1) the distinction between ecological and socio-economic values is much less obvious and most parameters scored highly. This may be attributed to the presence of a Bird Reserve situated close to the beach that naturally accounts for generally high scoring of ecological parameters. The positive scoring for human aspects at Mellieha Bay (Fig. 1) may be explained by the large size of the embayment which supports the largest sandy beach on the Maltese Islands, thus offering a high tourism related recreational potential. As with St. George's bay (Fig. 1) the hazard parameter at Mellieha Bay also scored highly due to exposure to northwest, north and northeasterly gale storms.

Function Analysis results for both Ghajn Tuffieha and Ramla Bay (Fig. 1, Plates 3 and 4) reflect a generally similar pattern. High scores were allocated to environmental parameters and low values to human aspects. However, some site-specific differences are evident but may be explained. In this context, the lower value allocated to the air quality parameter at Ramla Bay (Fig. 1) may be linked to the impact of an upwind municipal waste disposal site. 


\section{Site evaluation based on cons ervation value and use/development potential}

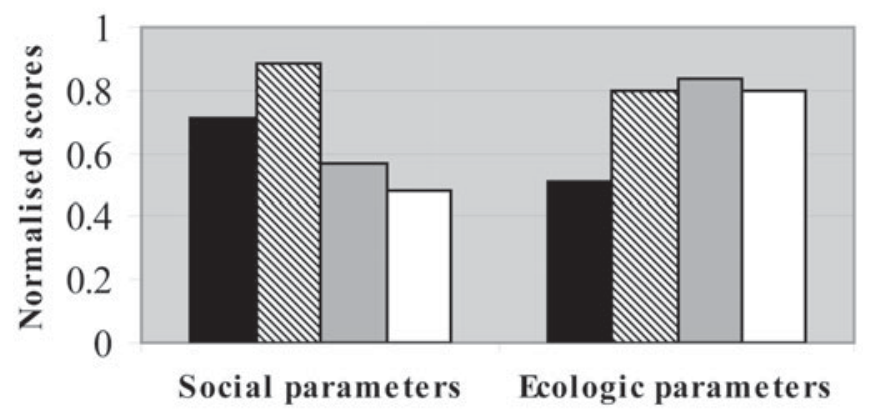

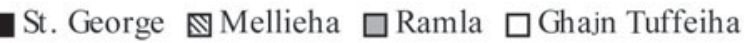

Fig. 2. A comparison of the conservation and use/development values of the four beaches evaluated.

At Ghajn Tuffieha (Fig. 1) coastal waters received lower rating due to occasional higher turbidity arising from the high clay content of the beach sand at this site. Similarly, the discrepancy in value allocation to the freshwater parameter (Fig. 1) may be attributed to the much larger water catchment area influencing Ramla Bay in Gozo.

Fig. 2 describes the overall conservation value versus the use/development potential of each of the beaches evaluated by comparatively illustrating the total normalized scores of the ecological and social values. St. George's Bay is described as having the lowest conservation value and the second highest use/ development potential of the four beaches evaluated. Fig. 2 also describes that as already reflected by the individual bathing area evaluation, Mellieha Bay was attributed high scores for both conservation value and use/development potential. This may be attributed to the presence of A Bird Reserve in the immediate hinterland of the beach that, on its own, would have scored poorly on conservation value. The bathing areas at Ramla and Ghajn Tuffieha both scored highly on conservation value and poorly on use/development potential.

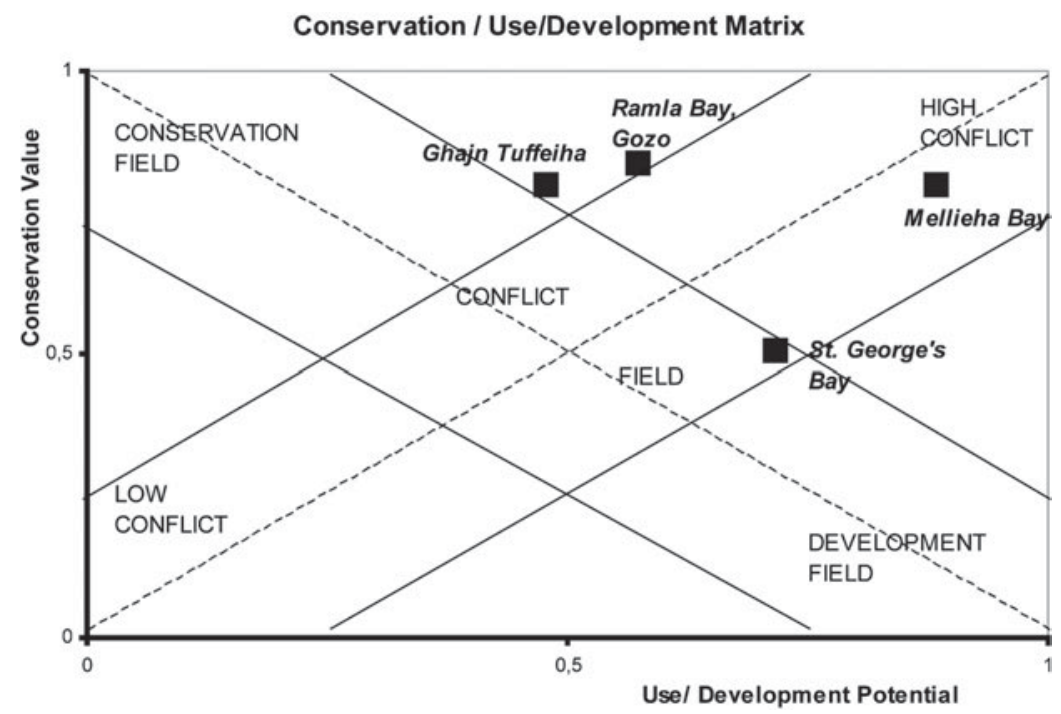

Fig. 3. Position of the four beaches evaluated within the Conservation / Use-Development matrix developed by Cendrero \& Fischer 1997). 


\section{Discussion}

In this study, field observations were supported by desk studies and data generated by various management techniques namely, Questionnaire Surveys on beach user preferences and priorities (Micallef et al. 1999; Anon. 2001; Blakemore et al. 2002) Dimensional Analysis (Micallef \& Williams 2002), Beach Registration \& Classification (Micallef 2002; Micallef \& Williams 2003). The above mentioned techniques provided information relevant to the evaluation of different ecologic and social beach components. For example, beach user questionnaire surveys address the direct value placed on various beach aspects by beach users while Dimension Analysis enables a clear consideration of the various beach components through an in-depth problem evaluation. Similarly, the process of beach registration provides extensive beach-related data and through classification, an evaluation of the importance of individual beach aspects (e.g. safety, water quality, facilities, scenery and litter) to the public. In a separate study (but based solely on visual observations carried out in the field), van der Weide et al. (1999) used the same approach to carry out a semi-quantitative evaluation of two coastal wetlands in Turkey. The authors concluded that the technique was able to represent baseline information on each site as well as reflect differences in coastal planning and management objectives for each site, thereby providing a basis for discussion on wetland value.

Fig. 3 shows the total normalized scores for conservation value and use/development potential for each beach, plotted as a matrix that allows site comparison and development of Integrated Coastal Area Management (ICAM) strategies. Points located in the bottom part of the matrix have low conservation values while those placed in the upper section have high conservation values. Similarly, values located in the left section of the matrix have low economic potential while those placed to the right side of the matrix reflect areas with a high potential for development.

In considering the most appropriate strategies to apply to an area, development priority should be allocated to areas placed at the bottom right of the matrix (i.e. high development potential and low conservation value). Van der Weide et al. (1999) suggested that in such circumstances, Environmental Impact Assessment procedures should be applied to confirm that any negative impacts on the conservation value of an area is within acceptable limits. Conversely, strict conservation measures should be applied to areas located in the upper left section of this matrix. The authors recommended that where areas fall in the conflicting sections of the matrix, indepth studies should be carried out to better define the conflicts and appropriate management strategy.

In this context, the matrix reveals that for the period 1999/2000, Ramla, Ghajn Tuffieha and Mellieha Bays had the higher conservation values and St. George's Bay the lowest conservation value (Fig. 3). It is interesting to note that Mellieha Bay (Plate 1) simultaneously exhibits high conservation value and use/development potential. This may be explained by the presence of both high recreational (beach) / tourist facilities (hotels, restaurants) as well as ecologically important Bird Reserve facilities at this site. As a consequence and as described by the matrix, the position of Mellieha Bay within the matrix falls within the high conflict area. It is in this area therefore, that good ICAM practice (finding a balance between conservation and development) is most necessary.

Since the ecologically important aspects at St. George's Bay (Plate 2) are limited to good water quality and biota-rich sea-grass meadows, conflicting interests between conservation value and use/ development potential are much reduced but not low. In comparison to Mellieha Bay therefore, the location of St. George's Bay in the matrix (Fig. 3) moves from the top right-hand corner (high conflict area) towards the bottom left-hand corner of the matrix (low conflict zone) but stopping about the middle section of this conflict field. Fig. 3 also describes St. George's Bay as being closest to the development field of the matrix (bottom right-hand corner), suggesting the suitability of a management policy with a recreation/ development bias for this area. This position is well supported by the highly developed nature of St. George's Bay and a recent study (Micallef \& Cassar 2001) that recommended St. George' Bay as a strong candidate for beach nourishment and recreational improvement. This recommendation arising from Function Analysis appears well supported by the results of a novel system proposed for bathing area classification (Micallef 2002) where St. George's Bay, in its present degraded state was awarded the lowest possible rating of 1 Star.

The higher conservation value rating allocated to Ramla over Ghajn Tuffieha Bay may be attributed to the ecologically important though albeit highly degraded sand dune remnants at Ramla Bay (Plate 4). The high conservation value awarded to both areas is well supported by their status as Areas of Ecological Importance (AEI) and nomination as potential marine conservation areas. Ghajn Tuffieha (Plate 3 ) is further protected by a recent awarding of a Conservation Order for this site that stipulates site-specific regula- 
tions for protection. A similar Conservation Order is being sought for Ramla Bay. The position of Ramla and Ghajn Tuffieha Bays within the conservation value/ use-development potential matrix indicates that an improvement in conservation value may be achieved at both sites and in this respect a management plan having high conservation bias is advocated. As with the findings for St. George's Bay, these results are supported by findings of a novel system proposed for bathing area classification (Micallef 2002) that similarly awarded the highest rating to Ghajn Tuffieha and Ramla Bays (four out of a possible five Stars).

In line with the findings of van der Weide et al. (1999), application of Function Analysis in this study was found to provide a clear representation of the varying characteristics of the four case study beaches examined. The increased clarity of distinction of the four beaches may be attributed to the increased data sets available, therefore improving on the semi-qualitative evaluation by van der Weide et al. (1999). A point of caution is raised with respect to the need to consider both temporal and spatial aspects of such environmental evaluation. The current study refers to a specific time frame when the evaluation was carried out (2000) and the period when relevant data was collected (1999-2000). The results presented clearly refer to a baseline situation for this period and any subsequent reference to environmental quality of areas surveyed should consider developments to date (both in terms of possible improvements or degradation). Therefore, this preliminary study represents a reference situation that should be used for re-evaluation purposes to identify the suitability of management regimes. Similarly, the spatial aspects of Functional Analysis must be considered, particularly if the exercise is to be used for site comparison purposes. In particular, the soundness of such a technique in comparing environmental quality of differently sized areas and ones having large differences in socio-economic and ecological characteristics should be investigated through further field trials.

The Conservation/Development diagram (Fig. 3) emphasizes the value of using the technique for identification of baseline reference situations and to evaluate changes over time. It may therefore be interpreted for site assessment and management guidance by providing:

- The baseline environmental quality of an area.

- A comparison of two (contrasting) areas for the identification of different planning and management strategies required.

- Identification of future development strategies.

- Options for increasing environmental quality and improving sustainable development of an area.
- An opportunity to implement subsequent monitoring of the impact of applied management.

Despite a shift towards some subjectivity of this proposed approach, results obtained appear extremely positive with respect to ease of application and conformity with real life scenarios and evaluation by other studies. Nonetheless, it is recommended that further research is required to satisfactorily address any question of subjectivity with scientifically sound methodology such as Fuzzy Logic (Ergin et al. 2001, 2003a, b). It is expected that this would improve the overall performance and validity of the Function Analysis technique.

It is also suggested that although the applicability of the original list of parameters evaluated by Cendrero \& Fischer (1997) has been improved by this study through adaptation to local characteristics, it is nonetheless considered that the socio-economic parameters remain under-represented and that the current list of parameters is biased towards the natural parameters. In this context, issues of coastal scenery and increased land value at the coast may be pertinent to this technique. Additionally, it may be argued that certain parameters presently listed as forming part of the environmental component (e.g. hazards and some of the resource parameters) may be better evaluated as contributing to human values. Conversely, the historic features currently evaluated as part of the social component may be considered to contribute to the conservation value of an area and as such should form an environmental component.

\section{Conclusion}

Function Analysis was presented as a technique facilitating appropriate development through characterization of an environment by its conservation value and use/development potential. In this respect, the technique was also described as one able to assess the sustainability of a proposed or active management plan. Within the context of bathing area management, Function Analysis was presented as a technique allowing a better understanding of strengths and weaknesses of each bathing area assessed (in terms of the ability of the natural environment to provide ecological and socio-economic functions). This paper provides a baseline study (year 2000) and provides a temporal axis for monitoring subsequent changes that are likely to occur within the spatial context of the physiographically small-scale Maltese Islands.

Through Function Analysis, the four beaches examined by this study were evaluated in terms of their potential for development and their conservation 
value, through consideration of predefined bathing area-related ecological and socio-economic parameters. It was demonstrated that a graphical representation of the value allocated to each parameter considered of importance to the provision of natural and socio-economic functions facilitated identification of those parameters that need to be addressed (in this case, low scoring parameters) in order to improve the overall ecological or socio-economic quality of that bathing area through appropriate management. Ramla, Ghajn Tuffieha and Mellieha Bays had the higher conservation values and St. George's Bay the lowest conservation value. Mellieha Bay simultaneously exhibited high conservation value and use/development potential.

The versatile nature of Function Analysis was demonstrated through its ability to evaluate not only individual sites, but also to compare several sites. This latter feature allowed the representation and comparison of the conservation value and use/development potential of the four beaches evaluated in an overall matrix on which ICAM strategies could be formulated. In addition, Function Analysis was observed to generate not only general comparative observations but also generate site-specific distinctions and recommendations.

As an aide to management, Function Analysis was considered as extremely useful and (in the proposed simplified format) easy to apply. Simplification of score allocation was considered to suggest a tendency to subjectivity that may require address through appropriate techniques such as Fuzzy Logic.

\section{References}

Anon. (Ministry for Tourism) 2001. Tourism Carrying Capacity Assessment of the Maltese Islands. Technical Report \& Executive Brief. Malta Tourism Authority, Valletta, MT.

Anastassova, L. 1996. Beach management. Lecture notes. In: MedCoast Fourth International Training Programme on Beach Management in the Mediterranean and the Black Sea, 11-17th May 1996, Gozo, Malta. MedCoast Secretariat, Middle East Technical University, Ankara, TR.

Blakemore, F.B., Williams, A.T., Coman, C., Micallef, A. \& Unal, O. 2002. Aspects of beach economics: Malta, Romania and Turkey. J. World Leisure. 42: 29-41.

Cendrero, A. \& Fischer, D.W. 1997. A procedure for assessing the environmental quality of coastal areas for planning and management. J. Coast. Res. 13: 732-744.

de Groot, R.S. 1992. Functions of nature. Evaluation of nature in environmental planning, management and decision making. Wolters-Noordhoff, Groningen, NL.

Ergin, A., Micallef, A. \& Williams, A.T. 2003a. Coastal scenic assessment in select areas of Turkey, Malta and the United Kingdom. Final Project Report, The British Council, Malta, Turkey.

Ergin, A., Micallef, A. \& Williams, A.T. 2003b. Coastal scenic evaluation - a pilot study of some Dalmatian areas. Report commissioned by the World Wildlife Fund, MedPO, Rome, IT.

Micallef, A. 2002. Development of a novel bathing area classification system. Ph.D. Thesis. University of Wales. Swansea Institute of Higher Education, University of Wales, UK.

Micallef, A. \& Cassar, M. (eds.) 2001. An environmental impact statement on the proposed beach nourishment project at Bajja ta' San Gorg, San Giljan, Malta. A Technical Report \& Non-Technical Summary, Malta Ministry for Tourism, St. Julians, Malta.

Micallef, A. \& Williams, A.T. 2002. Theoretical strategy considerations for beach management. J. Ocean Coast. Manage. 45: 261-275.

Micallef, A. \& Williams, A.T. 2003. Application of a novel bathing area evaluation (BArE) system - A pilot study of selected areas of the Dalmatian coast. Report commissioned by the World Wildlife Fund, MedPO, Rome, IT.

Micallef, A., Morgan, R. \& Williams, A.T. 1999. User preferences and priorities on Maltese beaches - Findings and potential importance for tourism. In: Randazzo, G. (ed.) Coastal Environment Management, EUCC - ITALY/ EUCC (CD-ROM), Leiden, NL.

van der Maarel, E. 1978. Ecological principles for physical planning. In: Holdgate, M.W. \& Woodman, M.J. (eds.) The breakdown and restoration of ecosystems, pp. 413450. Plenum Press, New York, NY, US.

van der Maarel, E. 1979. Environmental management of coastal dunes in the Netherlands. In: Jefferies, R.L. \& Davy, A.J. (eds.) Ecological processes in coastal environments, pp. 543-570. Blackwell, Oxford, UK.

van der Meulen, F. \& van der Weide, J. 1999. Unpublished 
lecture notes on: Functions of nature and environmental Function Evaluation. In: MedCoast Institute'99. (International Training Course on Coastal Zone Management, 1999). MedCoast Secretariat, Middle East Technical University, Ankara, TR. van der Weide, J., van der Meulen, F., Sarf, F., Gengic, S. \& Gabunia, M. 1999. Assessing the value of two coastal wetlands in Turkey. In: Ozhan, E. (ed.) MedCoast' 99 EMECS'99 Joint Conference on Land - Ocean Interactions: Managing Coastal Ecosystems, pp. 1009-1020. Antalya, Turkey. MedCoast Secreteriat, Middle East Technical University, Ankara, TR.

Received 8 October 2002; Revision received 25 June 2003;

Accepted 1 October 2003. Co-ordinating Editor: R. Paskoff. 